\title{
AS NUANÇAS TEATRAIS DA MÚSICA EM GOTA D’ÁGUA
}

Isabel Jasinski ${ }^{*}$

emprego da música no teatro moderno pode ser feito sob duas concepções do drama: a naturalista e a antinaturalista. A primeira prima pela imitação da realidade exterior; a segunda privilegia a caracterização do momento cênico, um recurso da teatralidade, no qual se perde a ilusão de que teatro é vida ${ }^{l}$. De qualquer forma, a música revela-se como elemento constituinte da representação, é importante enquanto recurso a ser usado para contribuir para o núcleo significativo da unidade estilística de uma peça teatral e para a mise-en-scène.

O poder sugestivo da música e do som de fundo pode acompanhar toda a peça ou realçar apenas uma situação ou um estado psicológico, pode concentrar-se sobre uma personagem e indicar a classe social a que pertence. ${ }^{2}$

* Universidade Federal do Paraná.

1 Sobre este aspecto ver BENTLEY, Eric. As duas tradiçð̃es da moderna dramaturgia. In: $O$ dramaturgo como pensador. Rio de Janeiro: Civilização Brasileira, 199 I.

2 GIRARD, Gilles; OUELLET, Réal. Música e som de fundo. In: $O$ universo do tcatro. Coimbra: Almedina, 1980, p. 25 
A música diferencia-se do som de fundo, mas pode compartilhar funções comuns pela capacidade sugestiva que possui. Devido a isso, torna-se recurso frequiente na arte dramática, segundo avaliam Gilles Girard e Réal Ouellet, para os quais um código musical pode funcionar como duplo código gestual (quando sugere uma atitude) ou como invocador de atmosfera. Ainda mais, no teatro chega a delimitar ou associar espaço, além de representar o tempo, passagem subjetiva ou determinação cronológica. A associação de todas essas possibilidades determina a sua relação como um discurso implícito às enunciações $\mathrm{e}$ ações dos personagens, atribuindo valor conectivo entre os elementos da representação.

Como parte integrante do espetáculo, ganhou força quando, no século XVIII, Mozart desenvolveu para a ópera a música psicologicamente complexa, novo estilo denominado clássico e considerado dramático, em oposição ao estilo barroco de arquitetura musical.

\begin{abstract}
(...) o novo estilo dinâmico tornou possível reunir elementos em contraste essencial que logo passaram a ser tratados como elementos em conflito essencial: mudanças abruptas de sentimentos eram a princípio justapostas e depois ajustadas e desenvolvidas até que uma resolução final se apresentasse. ${ }^{3}$
\end{abstract}

Desta maneira os compositores buscavam reforçar a tonalidade subjetiva do momento cênico, elaborando a integração som/palavra, centro do trabalho operístico, e incorporando a ação à continuidade musical.

Contrário ao efeito de hipnose resultante da unidade entre música e ação, em todas as suas acepções dramáticas, Brecht elaborou um teatro baseado em uma nova índole da relação palco/platéia. No seu Teatro Épico, um dos centros vitais da linguagem, para conceber a teatralidade da obra, eram os signos de encenação, entre eles a música. Promoveu a autonomia entre som e palavra que, estando individualizados, possibilitariam uma postura ativa e crítica do espectador. Para ele, a relação que a música mantinha com o texto era dialética porque podia constituir-se em contraste de registros emotivos, gerando descontinuidade temática.

3 KERMAN, Joseph. A ação e a continuidade musical. In: drama. Rio de Janeiro: Jorge Zahar, 1990, p. 83 . A ópera comos 
$O$ indivíduo-personagem e seu estado de espírito não eram respaldados pela música, pois não importava a sua subjetividade e sim os motores sociais que o levavam a ser esse indivíduo, núcleo de interesse enquanto fenômeno social. A relação dialética dos componentes do drama proporcionava o chamado efeito de estranhamento que resulta na postura distanciada (o chamado efeito V), porque:

(...) o curso da fábula é descontínuo; a unidade total é constituída de partes autônomas que permitem, e mesmo impõem, o confronto com os correspondentes elementos da realidade. esta maneira de representar extrai sua força de comparação com a realidade, isto e, dirige sempre seu olhar para a causalidade dos processos reproduzidos. ${ }^{4}$

Gota d'água ${ }^{5}$ recupera criticamente as compreensões de música e teatro das tendências dramáticas da Ópera e do Teatro Épico, conquistando elaboração particular na obra. O aproveitamento que Chico Buarque e Paulo Pontes fazem destes efeitos musicais é o que analisaremos neste trabalho.

Nessa peça as formas musicais, geralmente, são melódicas, mas usam também a harmonia minimalista de notas agudas ou graves alternadas com intervalos de ausência de som. $O$ resultado desse movimento sonoro harmônico é a pontuação da ação, marcando o tom da fala do personagem como, por exemplo, quando Joana desabafa para Jasão ${ }^{6}$. A enumeração que ela faz de tudo que realizou por seu ex-companheiro é irritantemente marcada pelo fundo musical, recuperando a essencialidade da mágoa da personagem, a agudeza da sua dor. No entanto, esse ritmo musical é substituido, na mesma fala, pela melodia de "Gota d'água", que dá título à peça, acompanhando a observação de Joana sobre a certeza do sucesso do samba, numa forma de auto-referência que expōe um dos valores da obra de autoria de Jasão para a dinâmica teatral dessa peça: a de estabelecer o contraponto do conteúdo da fala, ressaltando-o.

4 BRECHT, Bertolt. Apud PEIXOTO, Fernando. Brecht: Uma introdução ao teatro dialético. Rio de Janeiro: Paz e Terra, 1981, p. 195

5 BUARQUE, Chico; PONTES, Paulo. Gota d'água. 7. ed. Rio de Janeiro: Civilização Brasileira, 1978.

6 Id., p. 75. Daqui em diante, as páginas de Gơta d'água a que se faz referência estarāo indicadas entre parênteses. 
A função da música como fundo, definindo o tom da cena, é a que mais se verifica na peça. As formas utilizadas são as elaboradas como orquestra e como conjuntos menores de instrumentos em ritmos de samba e músicas cerimoniais do candomblé. São ritmos que definem a entonação da voz, complementam o significado do discurso, da ação, ou determinam o nível social dos personagens. A música da orquestra geralmente se relaciona à situação "superior" de Creonte e aqueles que estão à sua volta, simboliza a erudição de uma cultura "desenvolvida". A possível nobreza dessa forma musical contrasta com a hipocrisia dos personagens, mas complementa o sentido de poder da sua posição social. Como exemplo podemos considerar o acompanhamento musical da "cartilha da filosofia do bem sentar", no qual: "(A orquestra ataca a introdução com ritmo bem marcado; enquanto canta, Creonte vai ajeitando Jasão na cadeira)" (p. 35).

O ritmo do candomblé e o samba estão associados à cultura popular brasileira, são formas musicais constituintes do cotidiano, a que as pessoas mais simples recorrem para aliviar angústias, estabelecer atitudes ou alimentar esperanças, como na festa do carnaval, cujo valor na obra de Chico Buarque é avaliado por Affonso Romano de Sant'Anna: "O tratamento que recebe é o mesmo do rito e do mito. É um tempo-espaço em que a comunidade liberta todas as suas repressões, assumindo nas máscaras e nos disfarces a sua verdadeira identidade."7

Em correspondência significativa com o valor do rito e do mito carnavalesco, Joana recorre às divindades do candomblé com a intimidade do parentesco, familiaridade de quem não tem mais ninguém a quem recorrer para conseguir aquilo que deseja: vingança e dignidade. A ação grupal estabelecida na cerimônia é manifestada pelas vozes que acompanham a música ritualística, chegando ao êxtase como meio de se comunicar com o divino (p. 89).

$O$ batuque do samba, que faz fundo para o solilóquio denominado "Monólogo do povo", origem popular de Jasão (cuja ascensão é considerada traição por Joana), e reforça a posição social da mulher e o seu abandono diante do traidor. Novamente, a entrada do coro melódico no ritmo da música-tema, em momento

7 SANT'ANNA, Affonso Romano de. Chico Buarque: a música contra o silêncio. In: Música popular e moderna poesia brasileira. 2. ed. Petrópolis: Vozes, 1980. p. 102

8 Título que consta no disco gravado sobre a peça: FERREIRA, Bibi. Os melhores momentos de "Gota d'água". Música de Chico Buarque de Hollanda. RCA Víctor, Rio de Janeiro, n. $103.0212,1977$. 
específico da fala da personagem, sublinha o assunto de que está tratando e aumenta o seu significado, aquilo que Jasão vai perder, o combustível da sua criatividade que possibilitou a elaboração do samba-sucesso: “... é a ligação que você tem com a sua gente..." (p. 127).

O acompanhamento musical também define a entonação e o cadenciamento da voz do personagem, atribuindo-lhe o tom nostálgico, raivoso, irônico, alucinado, jocoso, revelador ou satisfeito, conforme a situação do enredo, contribuindo para a dramaticidade do contexto da história pela associação psicológica que a música possibilita ao conteúdo. O efeito foi usado por Mozart e Beethoven em suas óperas, estabelecendo o estilo dramático da música clássica, onde ação e música se coadunam ${ }^{9}$. O acento de fala marcado pela músicạ podemos verificar no trabalho frenético da percussão como fundo para conversa da personagem principal com as vizinhas (p. 45). A velocidade da música e da voz demonstra a obsessão da mulher abandonada juntamente com os filhos, e pode sugerir a iminência de uma atitude precipitada para salvaguardar a sua honra. Novamente recupera o primitivismo do som do batuque repetitivo, expressão do que o ser possui de mais íntimo e irracional.

A ironia propiciada pela música como fundo de acompanhamento fica muito aguda na penúltima cena da peça, quando acontece o clímax do drama (p. 167). É o momento em que Joana decide matar os filhos e' suicidar-se. A melodia de "Gota d'água" ganha novo significado, pois acompanha o discurso da utopia, do desejo do não-lugar para viver que marca a "...dissonância entre o indivíduo e as propostas de realidade que lhe fazem" ${ }^{10}$. No seu discurso, Joana exclui-se voluntariamente para fazer sofrer aquele que a fez sofrer, e o tom irônico se dá pela presença indireta da causa da sua desgraça: o samba de Jasão. A música segue o vislumbre de uma solução positiva para a situação, mas a sua suspensão, no momento em que a personagem oferece seu ato para os inimigos, significa o fechamento do estado de graça em que se encontrava para um retorno à realidade, caracterizando um movimento típico do trabalho musical de Chico Buarque. E essa suspensão musical ganha contraste em oposição ao desfecho da peça, marcado pelo deslanche precipitado da orquestra, quando Joana come finalmente o "naco de eternidade" que lhe cabe.

Outra maneira de acompanhar sonoramente a fala dos personagens é a repetição de um tema musical em momentos diferentes da história, cujo contraste canção/fundo associa sucintamente significados construídos. $\mathrm{O}$ que não

9 KERMAN, op. cit., p. 102

10 SANTANNA, op cit., p. 103 
acontece somente com o tema principal que dá título à obra, mas também com o ritmo de "Bem querer" como fundo para o solilóquio de Joana enquanto prepara o veneno destinado a Alma e Creonte (p. 160). A música representa a tomada de posição do homem amado diante da mulher amante e o desejo de vingança resultante do ato de exploração dela por ele. $O$ acompanhamento musical a esse momento de ação específico e significativo caracteriza a consumação da vingança.

Muitas vezes, a sonoplastia marca a espacialização da peça enquanto transição entre os sets e o contraste entre as atitudes dos diferentes personagens, o resultado desse recurso acaba por ser paradoxal já que traduz-se como uma maneira de conectar espaços e marcar trajetória, unindo-os, ao mesmo tempo que os liga como pontos de vista variados de uma mesma realidade, possibilitando o efeito $V$ brechtiano. Exemplo marcante dessa função é o momento em que vizinhas e vizinhos estão cantando "Gota d'água", acompanhando a música no rádio, e Joana entra em cena (p. 41). A conexão entre música e momento do enredo revela a diferença de valores entre os vizinhos e Joana e a diferença de situação de vida, ampliando a distância entre eles e o drama da mulher de forma muito óbvia, para gerar visualização crítica do momento.

Entretanto, a sonoplastia também funciona para revelar a passagem de tempo, que complementa a espacialização. A passagem pode acompanhar ação divergente, enquanto significa a dispersão dos personagens, ou convergente, como maneira de uni-los para um mesmo evento. Esse movimento complexo, relacionado à ópera, respalda a relação dramática do nível narrativo da história com a ação na representação. A parte da suíte (p.159) demonstra a forma de passagem de tempo com ação divergente. Por si essa organização rítmica já significa um conjunto de peças cuja ligação se justifica pelo contraste de andamentos musicais. São árias representativas do clima reinante em cada set, estruturação que modula contrastes rítmicos para caracterizar psicologicamente os personagens: alegria, paixão, reflexão ou silêncio, por contraposição, associados à suspensão da temporalidade do cotidiano ou à sua presença opressora. A divergência é ampliada pela oposição do tom ameaçador da presença de Joana, na sequiência, que prepara o veneno: "Agora, cada setor cantarola sua ária; BG; luz fica em resistência em todos os sets e acende, clara e brilhante, no set de Joana que, habilmente, tempera com ervas uns bolos de carne" (p. 160). O paradoxo estabelecido entre a alegria do povo e a angústia de Joana revela-se na síntese da relação dialética, gerada pela compreensão crítica global do espetáculo, apesar da carga emotiva intrínseca.

A transição temporal de ação convergente se realiza quando os personagens se movimentam, ainda cantando suas diferentes canções, em direção a um ambiente só: o casamento (p. 161). Cantam sublinhando a passagem do tempo 
de preparação para a festa que se traduz como o motivo de união dos personagens. O tempo de preparação é uma forma de alienação da realidade de opressão que sobrepassa todas aquelas vidas, resultando numa acomodação confortável que carrega a ilusão da melhora de vida e suspende a temporalidade mordaz daquele cotidiano. A situação torna-se irônica quando se confronta com a vida miserável c submissa que ameaçou prorromper em revolta e deixou-se, por fim, lograr ingenuamente pelo discurso populista de Creonte.

Durante a festa de casamento, a música é aproveitada conforme outra perspectiva funcional, encaixando-se na trama para ilustrar o enredo e justaporse aos diálogos. O trecho de "Flor da idade" (p. 162) propicia a coreografia em que os personagens se divertem na festa, dançando e cantando, contribuindo para o desempenho cênico do casamento. Anteriormente, em uma primeira ocasião, essa música é lançada figurando o momento de confraternização entre vizinhos e Jasão, no instante da sua visita (p. 61). Nesta, o teor de satisfaç̧ão por reencontrar o amigo que se deu bem é exteriorizado e reforçado pela inclusão da música, a realização desta pelo coro de vizinhos autoriza a sua autenticidade como forma espontânea de esboçar a vida que levam, ainda que lírica visão, em contraposição ao silêncio nada cúmplice de Jasão, que não compartilha da festa. A inadequação deste momento utópico, em relação à realidade suscitada pela história, produz novamente o efeito de distanciamento do teatro de Brecht. Mas o desconforto ameniza-se pela espacialização do boteco, que pressupõe alegria e descontração, ou exacerbamento das emoções. Girard c Ouellet observam que:

Em Brecht, a música revela-se autônoma em relação às palavras; de modo algum tautológica, entra, pelo contrário, em relaçāo dialéctica com um texto que pode ser contradito por ela uma vez que uma música arrebatadora contrasta significativamente com uma cena entristecedora. Em vez de se situar em um único registro afetivo, pode desentoar e constituir um apelo à inteligência crítica do espectador.

Assim, observamos o quanto Gota d'água se relaciona dialeticamente com as proposições do Teatro Épico sobre o uso da música, aproveitando efeitos 
mas relativizando-os por atribuir-lhes novas interpretações que não se relacionam com o estranhamento.

Outras vezes, a introdução da música-ilustração se faz por meio do rádio, marcando o seu papel como componente da ação, complementando a ação dos personagens e gerando a eficácia naturalista da representação. São dois os momentos mais evidentes desta forma de associação entre teatro e música. $\mathrm{O}$ primeiro é quando se apresenta o sucesso de Jasão no rádio, antes somente comentado pelos personagens. Em segundo lugar, por meio de Egeu, a música se faz presente novamente no rádio, quando sugere que Jasão, além de sambista, tem talento para mecânico de eletrodomésticos, já que ele havia mexido no aparelho buscando ajudar mestre Egeu, que lhe havia ensinado o ofício: "girando o botão, explode uma música no rádio que Jasão, enquanto falava, consertava; a orquestra executa uma variação do tema que sublinhou a fala sobre os filhos; Egeu dá um salto, percebendo que Jasão consertou o rádio" (p. 58). A recuperação de um tema musical citado anteriormente, o da obsessão que marcava a fala de Joana, associa o exemplo de Jasão como bom mecânico ao exemplo que, hipoteticamente, passou aos filhos, de irresponsabilidade diante da família, relacionando sentidos para criar ironia, sutilmente, porque a variação do tema faz observar a diferença de nível entre os significados do contexto. A recapitulação expõe o material original sob uma luz nova e marca outro recurso operístico, comentado por Joseph Kerman em A ópera como drama ${ }^{12}$.

No entanto, a realização de algumas músicas cumpre concomitantemente funções diferentes para o desempenho teatral de Gota d'água. É o caso de "Flor da idade", que alcança valor mais amplo que a temática da peça como documento cultural do povo brasileiro. Esse valor cultural é muito forte na obra musical de Chico Buarque enquanto busca no popular "a única fonte de identidade nacional" (p. XVI). Assim, essa música exemplifica o valor simbólico da arte popular, recupera liricamente a alegria do povo brasileiro e a sensualidade das suas mulheres. O ritmo de "Flor da idade" e a atuação dos personagens também consideram o arrebatamento utópico do ponto de vista do amor e da festa, eventos que colaboram para suplantar o vazio da falta de perspectiva do dia-a-dia. A música suspende o presente para revelar a intemporalidade do prazer, onde os excluídos e marginalizados passam a ser o centro da ação e sujeitos de suas atitudes. 
"Bem querer" é outra música que privilegia a função simbólica na trama da peça, por representar a expectativa de Joana diante de Jasão, mas também por figurar um tipo de relação homem/mulher que ultrapassa o individual para alcançar o estereótipo. O homem representa a ação do desejo de poder e a mulher, o objeto desse desejo, submisso por uma disposição social, mas que é capaz de agir pontualmente demonstrando a força contida durante a repressão de seu próprio poder. A morte resulta único conduto de direcionamento dessa energia para a libertação. A aceleração brusca da música no final marca esse desfecho precipitado que não oferece outra solução. A repetição da locução bem querer, em contraposição ao teor semântico do todo, gera nostalgia e ironia obsessiva da perspectiva feminina, que se acentua no contexto dramático pela posição que ocupam Joana e Jasão no palco, ela caminhando até sua casa e ele aparecendo do outro lado (p. 69).

Da sua parte, "Gota d'água" também cumpre papel simbólico, principalmente no fechamento desta "tragédia carioca", quando acompanha a projeção da manchete sensacionalista, estabelecendo o contraponto da tragédia e sua causa:

ASSASSINOU OS DOIS FILHOS E SE MATOU - Vingança macabra - Abandonada pelo amante Jasão, o famoso autor do grande sucesso "A gota d'água"-Quando ficou famoso preferiu a filha do rico bicheiro - Ciúme foi a causa do tresloucado gesto. $^{13}$

Novamente o significado é irônico pela comparação sucesso musical/êxito criminoso, estabelecida pela última rubrica do texto teatral. A síntese crítica proporcionada pela associação de signos distintos, a projeção e a música, revela a visão que os meios de comunicação de massa possuem do povo. Essa visão foi analisada pelos autores na apresentação à peça (p. xv) dizendo que o popular só aparece enquanto realidade nacional como ex6́tico, pitoresco (o samba) ou marginal (o crime). Fora dessas qualificações, deixa de ter voz; exemplo disso é o drama vivido por Joana, não reconhecido nem pelos seus vizinhos, também gente do povo.

13 Capa da edição da Civilização Brasileira. 
Então, um dos objetivos dessa obra é ser uma tentativa de retorno à fonte de criatividade do povo, criticando a visão limitada que os produtos culturais daquela época promoviam a respeito dele. Uma das formas de realizar esse desejo é recuperar ritmos musicais populares que se assemelham a cantigas de roda, como o refrão que marca a corrente de boatos coreografada.

Tira o coco e raspa o coco

Do coco faz a cocada

Se quiser contar me conte

Que eu ouço e nạ̃o conto nada (p. 78)

Seu valor nesse contexto dramático se realiza por simbolizar algo muito popular que é o movimento de uma comunidade (no caso, bairro ou vila) em torno a um acontecimento, por meio de uma comunicação rápida e comum: a fofoca. $O$ exagero quanto ao conteúdo do boato atribui-lhe valor cômico (parodiando o caráter natural da fofoca) e crítico do nível de poder de Creonte, em oposição à pobreza da população. O jogo de cruzamento de vozes faz ampliar o efeito da corrente de boatos como ecos, sintetizando numa cena aquele movimento comunitário de informação, simultâneo, caótico e popular, referido acima.

A música, muitas vezes, corresponde à elaboração narrativa da história, ou seja, ela substitui a fala de um personagem para ele dizer de sua subjetividade sob a forma musical, o que aumenta a emotividade e se relaciona à integração palavra/música e à complexidade musical da ópera. Isso acontece principalmente com "Gota d'água", cuja função no enredo é a de ser o estopim do desenvolvimento dramático da linha narrativa. Além de todos os outros significados que assume no desenvolvimento dramático da peça, realiza-se como expressão da melancolia dos personagens. Sob a voz de Joana, o sucesso musical de Jasão demonstra bem o significado trágico que o texto guarda. Posto neste contexto específico, ilumina semanticamente toda a trama e contribui para a organização narrativa da história, pois mostra-se como uma síntese do drama. Joana, revelando ter dominado a situação, conversa com seu ex-companheiro para fazer as pazes e assim efetivar a vingança. Então, depois que Jasão saiu, entra a orquestra e ela canta.

Já lhe dei meu corpo, não me servia Já estanquei meu sangue, quando fervia Olha a voz que me resta 


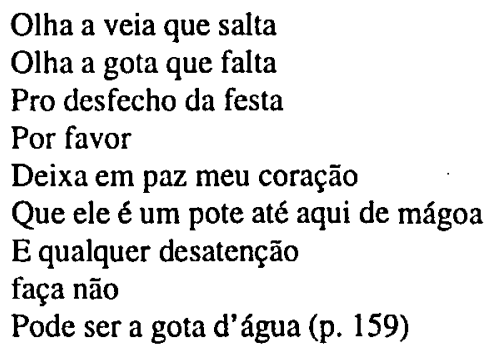

Assim, ela desabafa sua mágoa e atualiza em cena o valor da máxima popular, recuperando o tom ameaçador de seu amor desiludido. Seu cantar é como uma resposta à felicidade do traidor, ela está prevenindo: a realização do casamento será a gota d'água. E a melancolia é resultante do clima de despedida que impõe ao quadro, pois seu objetivo é a morte.

A tomada da posição de comando por parte de Joana é também representada por música, canção denominada "Basta um dia" (p. 151). Sua estratégia de ação é revelada neste instante em que a melodia constrói o sentido pela repetição do conceito só um dia, como verificação de sua conquista, e pelo crescendo intensificador do ritmo até a felicidade que pontua a primeira ação enquanto sujeito (não mais vítima): chamar Jasão e dizer que sua dor está passando. Os versos curtos demonstram a velocidade da ação e a alternância violão/orquestra marca a variação de temperamento de Joana, o da solidão e o da ameaça. Resultado disso é a síntese da sua situação que proporciona a epifania para o desencadeamento final do drama.

Pela análise realizada, verificamos que a elaboração da peça Gota d'água sustenta-se sobre um trabalho racionalista que respalda os objetivos dos autores de atuação cultural na sociedade brasileira do ano de 1976, quando foi representada. Esses objetivos cumprem-se com mais eficiência se os elementos envolvidos na construção de sentido da obra forem engrenados segundo uma certa precisão, ou seja, cada um fornecendo sua capacidade expressiva para o todo de forma a fazê-lo desempenhar sua força como produto particularizado. O espectador vai cumprir o papel de complementar a racionalização, ainda quando sua emotividade seja provocada até o auge em que uma mãe mata os próprios filhos. Sua revolta íntima também é o objetivo de quem dá a corda à engrenagem porque exige que ele tome um posicionamento diante da situação, antecipada pelo impasse ficcional que provoca suspense e ansiedade.

Se compreendermos sintaxe teatral como o processo de significação da obra que se baseia no sistema de relações entre a ação dos personagens, sua contextualização em determinado espaço e tempo, segundo um enredo, uma 
ordem, podemos dizer que a música cumpre o papel dos elementos conectivos no texto dramático da peça analisada. Ela preenche a parte de ligação entre os inúmeros elementos significativos, atando-os no momento da representação enquanto acompanhamento ou ilustração, ou marcando a ação na história, como narração, e na História, como símbolo de uma ideologia cultural.

Gota d'água mescla a música como recurso naturalista que contribui para a veracidade da história com seu aspecto antinaturalista da teatralidade, que amplia a carga psicológica dos personagens e a emotiva dos espectadores. $\mathrm{Na}$ totalidade, a música mostra-se componente imanente da significação.

\section{RESUMO}

O uso da música em Gota d'água se realiza em harmonia com a ação pelo fato de ter sido escrita conjuntamente com a história pelo compositor Chico Buarque em co-autoria com Paulo Pontes. Ela é parte intrínseca da obra e aproxima-se do uso que a opera faz deste recurso artístico, hipnotizando o espectador pela unidade som/palavra. Por outro lado, quebra a sua passividade pelo distanciamento brechtiano quando estabelece relação dialética entre momentos diferentes do enredo e entre contexto e ritmo dissonantes. A música nessa peça liga os elementos significativos enquanto acompanhamento ou ilustração, marcando a ação na história, como narração, e na História, como símbolo de uma ideologia cultural.

Palavras-chave: Teatro Brasileiro Contemporâneo; Música; Chico Buarque de Hollanda e Paulo Pontes.

\section{RESUMEN}

El uso de la música en Gota d'água se realiza en armonía con la acción debido al hecho de que fue escrita por el compositor Chico Buarque en coautoría con Paulo Pontes. Ella es parte intrínseca de la obra y se acerca del uso que hace la ópera de este recurso artístico, hipnotizando el espectador a través de la unión entre sonido y palabra. Por otra parte, rompe su pasividad por el alejamiento brechtiano cuando establece relación dialéctica entre momentos distintos del enredo y entre contexto y ritmo disonantes. La música conecta a los elementos significativos en cuanto acompañamiento o ilustración, inscribiendo la acción en la historia, como narración, y en la Historia, como símbolo de una ideología cultural. 


\section{REFERÊNCIAS BIBLIOGRÁFICAS}

BENTLEY, Eric. As duas tradições da moderna dramaturgia. In: 0 dramaturgo como pensador. Rio de Janeiro: Civilização Brasileira, 1991. 43-63 p.

BUARQUE, Chico; PONTES, Paulo. Gota d'água. 7. ed. Rio de Janeiro: Civilização Brasileira, 1978.

FERREIRA, Bibi. Os melhores momentos de Gota d'água. Música de Chico Buarque de Hollanda. RCA Víctor, Rio de Janeiro, n. 103.0212, 1977.

GIRARD, Gilles; OUELLET, Réal. Música e som de fundo. In: Ouniverso do teatro. Coimbra: Almedina, 1980, p. 83-87.

KERMAN, Joseph. A ação e a continuidade musical. In: A ópera como drama. Rio de Janeiro: Jorge Zahar, 1990.

PEIXOTO, Fernando. Brecht: Uma introdução ao teatro dialético. Rio de Janeiro: Paz e Terra, 1981. (Coleção Teatro, v. 6)

SANT'ANNA, Affonso Romano de. Chico Buarque: a música contra o silêncio. In: . Música popular e moderna poesia brasileira. 2. ed. Petrópolis: Vozes, 1980. 2. ed, p. 99-104. 